\title{
Joint effects of long-chain branching and specific nucleation on morphology and thermal properties of polypropylene blends
}

\author{
L. Gajzlerova*, J. Navratilova, A. Ryzi, T. Slabenakova, R. Cermak \\ Tomas Bata University in Zlin, Faculty of Technology, Vavreckova 275, 76001 Zlin, Czech Republic
}

Received 6 January 2020; accepted in revised form 22 March 2020

\begin{abstract}
The influence of long-chain branching and specific $\beta$-nucleation on polymorphic composition, melting and crystallization, and morphology of polypropylene blends were investigated by wide-angle X-ray scattering, differential scanning calorimetry, and scanning electron microscopy. Linear polypropylene and long-chain branched polypropylene were used for the preparation of blends in various proportions. $N, N^{\prime}$-dicyclohexylnaphthalene-2,6-dicarboxamide was introduced ( 0 or $0.03 \mathrm{wt} \%$ ) as a $\beta$-specific nucleating agent into prepared blends. It was found that LCB-PP strongly induces $\gamma$-phase formation in the blends and suppresses the nucleation activity of a $\beta$-specific nucleating agent. Blends containing a predominant amount of $\alpha$ - and $\gamma$-phases showed higher thermodynamic stability within melting, as compared to the samples rich in $\beta$-phase. During crystallization, LCB-PP in the blends increases nucleation density by self-seeding effect, manifesting itself in the shift of crystallization temperature. $\beta$-phase in the blends is distinctly separated in spherulites, while $\alpha$ - and $\gamma$-phases coexist on the lamellae level.
\end{abstract}

Keywords: polymer blends and alloys, polypropylene, long-chain branching, specific nucleation, thermal properties

\section{Introduction}

Isotactic polypropylene (PP) possesses a prominent position among semi-crystalline polymers, which is mainly a result of its structural behavior. It implies a good mechanical performance in engineering applications. However, commercial production of polypropylene with Ziegler-Natta or metallocene catalysts results in highly linear chains, relatively low melt strength, and extensional viscosity. These characteristics bring drawbacks for processes that require high melt strength, such as foaming, blown film processing, blow molding, and thermoforming [1-4]. The use of long-chain branched polypropylene (LCB$\mathrm{PP})$, recently developed and commercially available, prevents these problems and has opened up a wider field of applications. Long-chain branches are commonly introduced to linear polypropylene via direct synthesis using metallocene catalysis [5, 6], electron beam, or gamma irradiation $[7,8]$, and post reactor chemical modification $[9,10]$. However, a higher price of LCB-PP has complicated their widespread use in industry. Thus, production of blends of linear isotactic polypropylene and LCB-PP can provide satisfactory properties at a reasonable price $[11,12]$. Several crystallographic modifications have been recognized in $\mathrm{PP}-\alpha-, \beta-, \gamma$-phases, $[13,14]$, and the mesomorphic 'smectic' phase, which is formed during high undercooling instead of a crystalline phase $[14,15]$. From a practical point of view, monoclinic $\alpha$ - and trigonal $\beta$-phases have relevance $[16,17]$. The $\beta$-phase is thermodynamically metastable and difficult to obtain under normal processing conditions. Specific nucleation caused by an addition of heterogeneous $\beta$-nucleating agent is an efficient way of 
introducing the $\beta$-phase into the PP [17-21]. This crystallographic modification shows superior toughness and drawability but slightly lower stiffness as compared to the more common $\alpha$-phase [18, 22-26]. Obadal and coworkers [27-29] intensively studied lower sensitivity of $\beta$-nucleated polypropylene to photodegradation. Orthorhombic $\gamma$-phase is the most peculiar crystallographic modification of PP. It can be generated either by crystallization of a homopolymer at high pressure or by crystallization of low molecular weight fractions of PP and polypropylene-derived copolymers at atmospheric pressure. The $\gamma$-modification is especially favored in PP synthesized by metallocene catalysts, because of the presence of errors homogeneously distributed among the polymer chains [30-33]. Over the past two decades, many papers have focused on the role of long-chain branching in the crystallization of PP into the $\gamma$-phase [3439]. Su et al. [34] found that LCB-PP crystallizes from the melt as a mixture of the $\alpha$ - and $\gamma$-phases. The content of the $\gamma$-phase increases in LCB-PP with increasing crystallization temperature until it reaches a maximum value. Agarwal et al. [35] studied the shear-induced crystallization of LCB-PP. They found that $\gamma$-phase content is independent of long-chain branching level and induced by regional defects of the chain and shear flow. According to Zeng et al. [36], long-chain branching in PP increases the number of nuclei and decreases the activation energy of nucleation as a result of enhanced chain entanglement.

Controlling the molecular and supermolecular structure of polymorphic semi-crystalline polymers is a smart way of tailoring their properties. A combination of long-chain branched and $\beta$-nucleated polypropylene can bring interesting results - enhanced toughness and, at the same time, higher melt strength. Current papers focus on the rheological properties and chemical structure of PP/LCB-PP blends [4, 37, 38], while the crystallization behavior, morphology, and mechanical properties, which are important in applications, have been reported by few authors. Wang et al. [39] investigated the crystallization behavior and crystalline morphology of PP/LCB-PP blends. They found that the nucleation and overall crystallization rate are enhanced after the incorporation of LCB-PP into PP. Cao et al. [40] observed synergistic toughening effect of $\beta$-nucleating agent and long-chain branching on polypropylene random copolymer. Yu et al. [41] focused on evolution of $\beta$-crystals and better foamability of various L-PP/LCB-PP blends.

The goal of the present study is to examine the effect of long-chain branching and $\beta$-specific nucleation on the supermolecular structure and thermal properties of polypropylene blends. For these purposes, polypropylene blends with various amounts of LCB-PP, and the nucleating agent have been chosen. This approach should open new insight into the mechanism of blending and specific nucleation process and, at the same time, bring about practical instructions important for optimizing processing technology.

\section{Experimental section}

As starting materials, two types of commercially available polypropylenes supplied by Borealis Company Vienna, Austria, were used throughout this study. The first was linear polypropylene homopolymer Borclean HC310BF (L-PP). The second material used in this study was long-chain branched polypropylene Daploy WB130HMS (LCB-PP). It is a propylene-based polymer produced by monomer grafting during the radical-driven reactions of isotactic polypropylene with peroxides to create longchain branches. The materials have the value of melt flow rate $\left(230^{\circ} \mathrm{C}, 2.16 \mathrm{~kg}\right.$, ISO 1133) of 2.2 , and $2.8 \mathrm{~g} / 10 \mathrm{~min}$, respectively. Specific nucleating agent $N, N^{\prime}$-dicyclohexylnapthalene-2,6-dicarboxamide, $\mathrm{NJ}$ Star NU 100 (NU 100), was supplied by Rika Int., Manchester, Great Britain.

Blends containing different amount of LCB-PP $(0,1$, $2,5,10,20,50$ and $100 \mathrm{wt} \%)$ and NU 100 (0 or $0.03 \mathrm{wt} \%$ ) were prepared using a co-rotating twinscrew extruder (Brabender GmbH \& Co, Germany) followed by cooling and pelletizing. The processing conditions were as follows: screw speed $65 \mathrm{~min}^{-1}$, temperatures of barrel zones 190,200 , and $210^{\circ} \mathrm{C}$. To ensure the same processing history for all samples,

Table 1. Compositions of prepared blends.

\begin{tabular}{|l|c|c|c|c|c|c|c|c|}
\hline $\begin{array}{c}\text { Sample } \\
\text { [wt\%] }\end{array}$ & L-PP & BL 1 & BL 2 & BL 5 & BL 10 & BL 20 & BL 50 & LCB-PP \\
\hline L-PP & 100 & 99 & 98 & 95 & 90 & 80 & 50 & 0 \\
\hline LCB-PP & 0 & 1 & 2 & 5 & 10 & 20 & 50 & 100 \\
\hline NU 100 & $0 / 0.03$ & $0 / 0.03$ & $0 / 0.03$ & $0 / 0.03$ & $0 / 0.03$ & $0 / 0.03$ & $0 / 0.03$ & $0 / 0.03$ \\
\hline
\end{tabular}


unblended components were extruded under the same conditions. The compositions of prepared blends are listed in Table 1. From the prepared blends plates of a thickness of approx. $1 \mathrm{~mm}$ were compression-molded: pressing temperature $210^{\circ} \mathrm{C}$ for $5 \mathrm{~min}$ and cooling temperature $60^{\circ} \mathrm{C}$ for $5 \mathrm{~min}$. Subsequently, the specimens were examined by wide-angle X-ray scattering (WAXS), differential scanning calorimetry (DSC), and scanning electron microscopy (SEM).

The amount and polymorphic composition of the crystalline portion was determined by wide-angle X-ray scattering. An X'Pert PRO diffractometer (Malvern PANanalytical, United Kingdom) with Bragg-Brentano geometry in reflection mode was equipped with $\mathrm{CuK}_{\alpha}$ radiation with Ni filter $(\lambda=$ $0.154 \mathrm{~nm}$ ) and employed in the diffraction angle interval of $2 \theta=5-30^{\circ}$.

Overall crystallinity of all samples was estimated from the diffractograms after subtraction of the amorphous halo. The ratio of the integral intensities diffracted by a crystalline part $\left(I_{\mathrm{C}}\right)$ and amorphous part $\left(I_{\mathrm{A}}\right)$ was used to determine crystallinity $(X)$, see Equation (1):

$X=\frac{I_{\mathrm{C}}}{I_{\mathrm{C}}+I_{\mathrm{A}}} \cdot 100[\%]$

For a quantitative evaluation of the phase composition in $\beta / \alpha$ and $\gamma / \alpha$ crystalline systems of polypropylene, two basic relations can be used. In the $\beta / \alpha$ crystalline system, the relative content of the $\beta$-phase $(B)$ within the crystalline portion of the material is calculated according to Turner Jones et al. [19] by Equation (2):

$B=\frac{H_{\beta}}{H_{\alpha 1}+H_{\alpha 2}+H_{\alpha 3}+H_{\beta}} \cdot 100 \quad[\%]$

where $H_{\alpha 1}, H_{\alpha 2}, H_{\alpha 3}$ are the intensities of $\alpha$-diffraction peaks corresponding to angles $2 \theta=14.20,17.00$, and $18.80^{\circ}$, respectively, and $H_{\beta}$ is the intensity of the $\beta$-peak at $2 \theta=16.20^{\circ}$.

In the $\gamma / \alpha$ crystalline system, the reflections at $2 \theta=$ $14.2,17.0^{\circ}\left(H_{\alpha 1}\right.$ and $\left.H_{\alpha 2}\right)$, are common for both the $\alpha$ - and the $\gamma$-phases. Therefore, the $\gamma$-phase fraction $(G)$ within the crystalline part is calculated according to Sauner and Pae [42] only from the intensities of the (130) $\alpha 3$ reflection at $18.80^{\circ}\left(H_{\alpha 3}\right)$ and the (117) $\gamma$ reflection at $20.05^{\circ}\left(H_{\gamma}\right)$, which are unique reflections for each phase, as shown by Equation (3):

$G=\frac{H_{\gamma}}{H_{\alpha 3}+H_{\gamma}} \cdot 100[\%]$
The evaluation of an $\alpha / \beta / \gamma$ crystalline system can be calculated according to Obadal et al. [43], as follows:

1) The spectra of the $\alpha / \beta / \gamma$ crystalline system consist of all the reflections mentioned above: at diffraction angle $2 \theta=14.20^{\circ}$ ( $\alpha$ - and $\gamma$-phases), $16.20^{\circ}$ ( $\beta$-phase), $17.00^{\circ}\left(\alpha\right.$ - and $\gamma$-phases), $18.80^{\circ}$ ( $\alpha$-phase), and $20.05^{\circ}(\gamma$-phase). Since the spectra of the pure $\beta$-phase manifests only the reflection at $2 \theta=16.20^{\circ}$, and, on the other hand, the spectra of the $\gamma / \alpha$ crystalline system display solely the individual and shared reflections of the $\alpha$ - and $\gamma$-phases, Equation (2) has to be modified by the addition of $H_{\gamma}$ as shown by Equation (4):

$K_{\beta}=\frac{H_{\beta}}{H_{\alpha 1}+H_{\alpha 2}+H_{\alpha 3}+H_{\beta}+H_{\gamma}} \cdot 100 \quad[\%]$

where $K_{\beta}$ provides relative the $\beta$-phase content in the three-phase crystalline system of polypropylene.

2) Shared content of both $\alpha$ - and $\gamma$-phases $\left(K_{\alpha+\gamma}\right)$ in the three-phase crystalline system can be defined by Equation (5):

$$
K_{\alpha+\gamma}=1-K_{\beta}
$$

3) The mutual relation between the $\alpha$ - and $\gamma$-phases $(G)$ is calculated from the already mentioned Equation (3). Consequently, the content of the $\alpha$-phase $\left(K_{\alpha}\right)$ and the $\gamma$-phase $\left(K_{\gamma}\right)$ in the threephase crystalline polypropylene can be calculated by Equations (6) and (7):

$$
\begin{aligned}
& K_{\gamma}=G \cdot K_{\alpha+\gamma} \\
& K_{\alpha}=1-K_{\beta}-K_{\gamma}
\end{aligned}
$$

In an above-mentioned way, the polymorphic composition in three-phase crystalline systems of polypropylene is calculated only relatively; however, the results can be used for simple quantification of multiphase crystalline systems. More accurate results can be reached using an improved method by Krache et al. [31].

The melting behavior of the specimens was measured by a DSC1, differential scanning calorimeter (Mettler Toledo, USA). The specimens with a mass of approx. $7 \mathrm{mg}$ were inserted into standard aluminum pans and heated from 50 up to $190^{\circ} \mathrm{C}$ with a heating rate of $10^{\circ} \mathrm{C} / \mathrm{min}$. The measurements were performed under a nitrogen atmosphere $(20 \mathrm{ml} / \mathrm{s})$. 
Morphology of the specimens was directly documented by a Vega-II LMU scanning electron microscope (Tescan Company, USA). Compression-moulded plates were cryo-fractured under liquid nitrogen; fracture surfaces were then exposed to a permanganic etching $\left(1 \% \mathrm{KMnO}_{4}\right.$ in concentrated $\left.\mathrm{H}_{3} \mathrm{PO}_{4}\right)$ and finally sputtered with gold-palladium alloy.

\section{Results and discussion}

\subsection{Polymorphic composition of the blends}

X-ray diffractograms of L-PP/LCB-PP blends with/ without NU 100 are presented in Figure 1. What can be seen are typical diffraction spectra of three-phase crystalline systems manifested by the occurrence of the peaks of the main planes of the $\alpha$-phase $\alpha_{1}(110), \alpha_{2}(040)$ and $\alpha_{3}$ (130), $\beta$-phase (300) and $\gamma$-phase (117).

The overall crystallinity (Figure 2) of all samples was slightly higher than $50 \%$, independently on blend composition. The addition of $\beta$-specific nucleator NU 100 distinctly changes the crystallinity only in the pure LCB-PP: it increases from 48 to 53\%. The lower

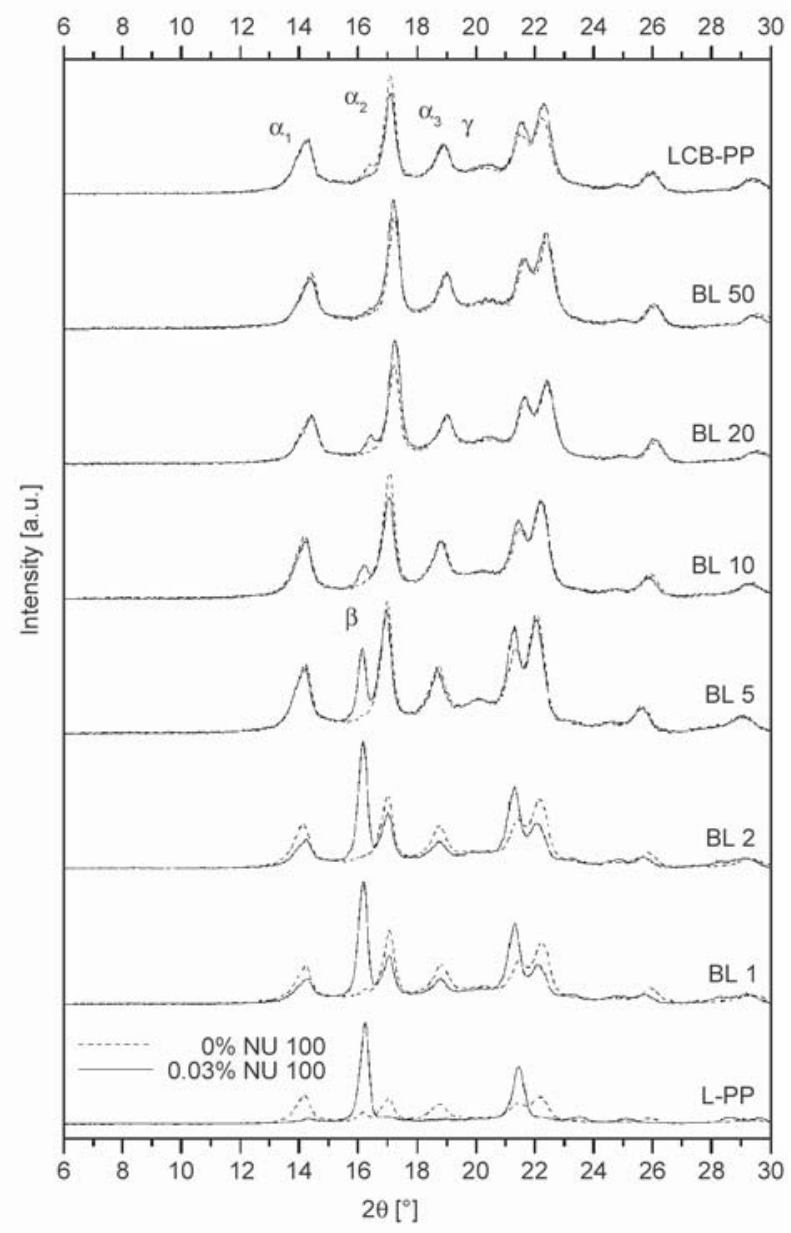

Figure 1. X-ray diffraction patterns of the blends.

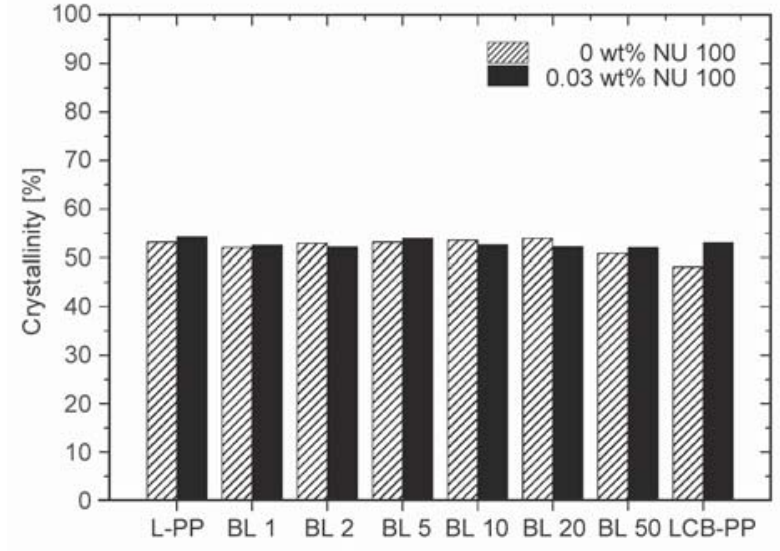

Figure 2. Dependence of crystallinity on the blend composition.

value of crystallinity in the case of pure LCB-PP can be ascribed to the fact that the long chains act as defects restricting crystalline packing. For the quantitative description of individual phase content, the $K$ values defined by Equation (2)-(7) were calculated.

A strong dependence of polymorphism of the samples on the composition of the blend is evident from Figure 3. Neat L-PP consists predominantly of monoclinic $\alpha$-phase, whereas the addition of $0.03 \mathrm{wt} \%$ of NU 100 leads to the crystallization of L-PP into almost solely trigonal $\beta$-phase $\left(K_{\beta}=94 \%\right)$. This effect has already been published (e.g. $[17,23,24])$. On the other hand, neat LCB-PP consists largely of monoclinic $\alpha$ - and orthorhombic $\gamma$-phases $\left(K_{\gamma}=\right.$ $26 \%$ ), $\beta$-phase content $K_{\beta}$ is only $7 \%$. In the nucleated LCB-PP $\beta$-phase vanished absolutely. Thus, it is evident that $\beta$-specific nucleator NU 100 does not induce the crystallization into the trigonal $\beta$-phase in LCB-PP under given conditions. In the case of nucleated L-PP/LCB-PP blends, the significant decrease of $\beta$-phase content with increasing LCB-PP amount can be observed, from nucleated BL $1 K_{\beta}=$ $59 \%$ to BL 50 where the $\beta$-phase is suppressed

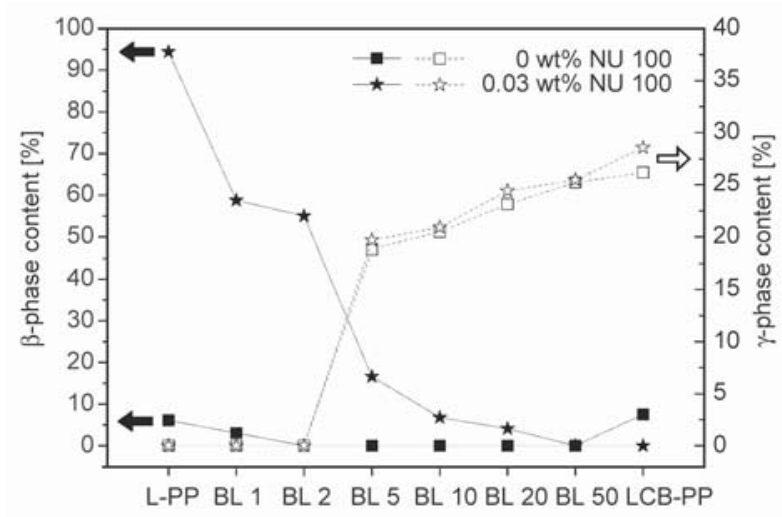

Figure 3. Dependence of $\beta$ - and $\gamma$-phases content on the blend composition. 
completely and the crystalline system consists only of $\alpha$ - and $\gamma$-phases. It is worth mentioning that even a small addition of LCB-PP to L-PP results in significant suppression of $\beta$-phase. An opposite trend is evident in the case of $\gamma$-phase of L-PP/LCB-PP blends independently on the $\beta$-nucleator concentration. The $\gamma$-phase content rises from $0 \%$ of L-PP and blends with low content of LCB-PP (BL 1 and BL 2) to almost $30 \%$ at LCB-PP. The sharpest increase of $K_{\gamma}$ can be clearly seen between blend BL 2 and BL 5, respectively. It is evident that the $\beta$-nucleating agent does not influence the formation of orthorhombic $\gamma$-phase. These results are in agreement with the work by Jeon et al. [44] who studied the effect of comonomer type on the crystalline structure of random isotactic propylene 1-alkene copolymers and observed that the development of $\gamma$-phase is enhanced in copolymers with increasing comonomer content, following the general concept that the increase in short crystallisable sequences favours the formation of the $\gamma$-phase $[34,45,46]$.

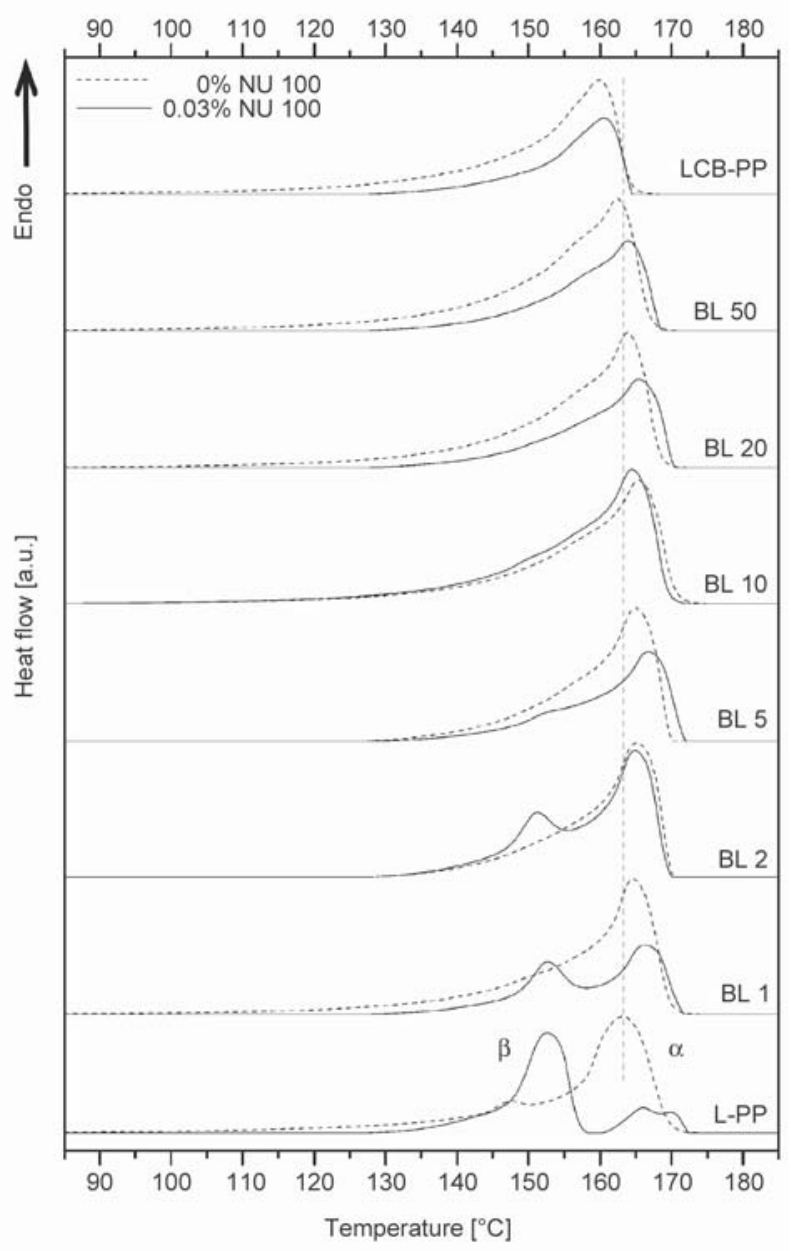

Figure 4. Melting thermograms of the blends.

\subsection{Melting and crystallization behavior of the blends}

The effect of blends composition on the phase structure is also manifested by the DSC thermograms (Figures 4 and 5). Melting thermograms of the L-PP/ LCB-PP blends are illustrated in Figure 4. It is evident that melting curves of blends without a nucleating agent have only one melting peak, which should be ascribed to the melting of the $\alpha$-crystallites. Only the neat material L-PP shows a small peak corresponding to the $\beta$-crystallites (melting temperature $T_{\mathrm{m}}$ at $149^{\circ} \mathrm{C}$ ). With an increasing amount of LCB-PP in the blends, the melting temperature first slightly increases up to BL 10, while further addition reduces it. A similar trend for the melting point of L-PP/ LCB-PP blends has been reported by Tabatabaei et al. [37]. However, McCallum et al. [4] reported drops of $T_{\mathrm{m}}$ of all blends compared with L-PP.

In the case of $\beta$-nucleated samples, the effect of blend composition is expressed in the different shape of the melting curves. Melting curve of the $\beta$-nucleated

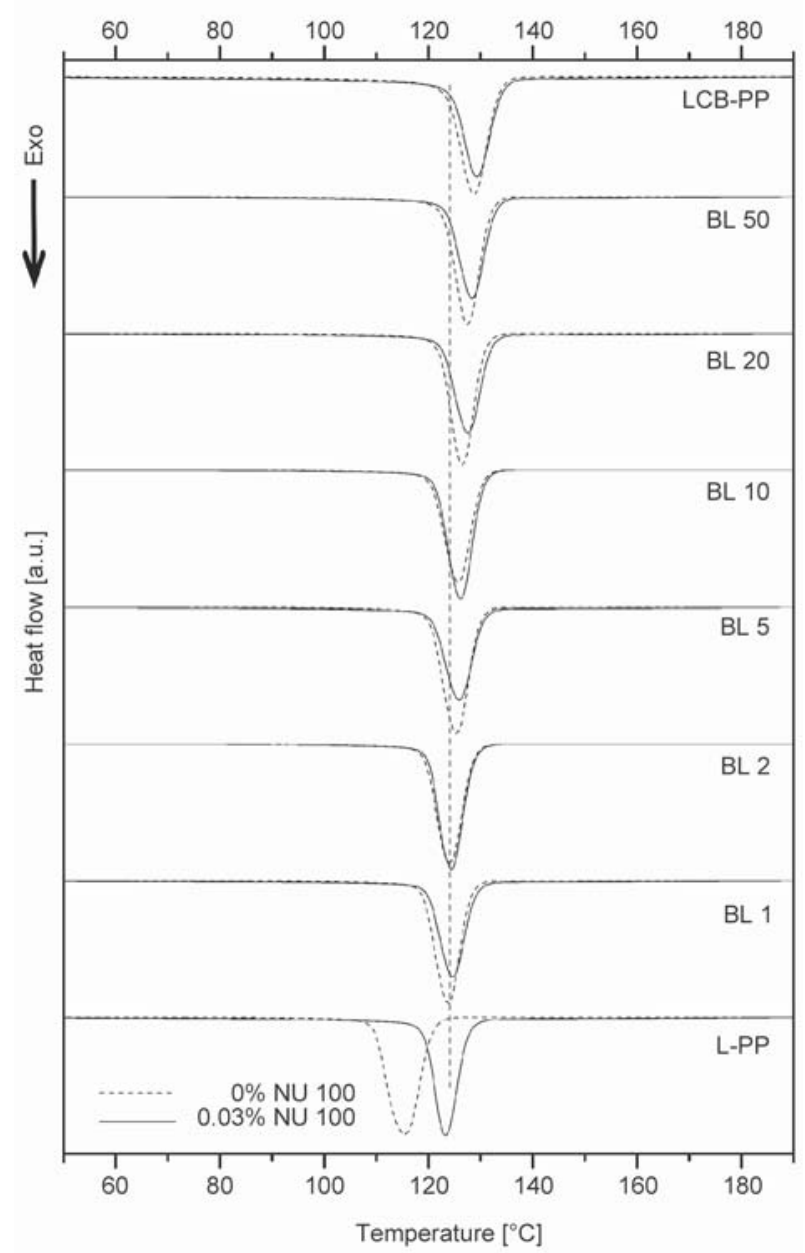

Figure 5. Cooling thermograms of the blends. 
L-PP shows a predominant $\beta$-melting peak at $152^{\circ} \mathrm{C}$ and less visible double $\alpha$-melting peak at 170 and $166^{\circ} \mathrm{C}$, respectively, which were formed during recrystallization process $[20,28]$. However, even a small addition of LCB-PP to the L-PP/LCB-PP blend leads to a significant drop of the $\beta$-melting peak. This $\beta$-melting peak disappears with the addition of only $10 \mathrm{wt} \%$ of LCB-PP. A slight decrease of $T_{\mathrm{m}}$ of $\alpha$-phase with increasing LCB-PP content in L-PP/LCB-PP blends can be observed, similarly as in the case of blends without a $\beta$-nucleating agent. Slightly higher melting temperatures of nucleated blends in comparison with blends without nucleating agents can be ascribed to the recrystallization process, which is more pronounced in the case of nucleated materials. These results correlate well with the WAXS data.

Figure 5 shows the cooling DSC curves of L-PP and LCB-PP blends with/without a nucleating agent. The crystallization temperature $\left(T_{\mathrm{c}}\right)$ of neat L-PP $\left(116^{\circ} \mathrm{C}\right)$ is much lower than that of neat LCB-PP $\left(130^{\circ} \mathrm{C}\right)$. It is evident that with a rising amount of LCB-PP in L-PP/LCB-PP blends, the crystallization temperature increases. The addition of only $1 \mathrm{wt} \%$ of LCB-PP to the L-PP leads to an increase of $T_{\mathrm{c}}$ to $125^{\circ} \mathrm{C}$. These results suggest that the crystallization ability of the blends is controlled by LCB-PP content. An obvious increase of the crystallization temperature of L-PP can be seen after the addition of a nucleating agent ( $T_{\mathrm{c}}$ come up to $125^{\circ} \mathrm{C}$ ). Much less noticeable change of crystallization temperature with the addition of a nucleating agent can be observed in the case of LCB-PP and L-PP/LCB-PP blends, respectively. The increase is approximately $1^{\circ} \mathrm{C}$. A similar phenomenon was observed by Yu et al. [41] with the $\beta$-nucleating agent (trade name V8) in L-PP/LCB-PP blends.

Higher crystallization temperature of LCB-PP can be assigned to long branches, which can have a selfseeding effect and thus speed the overall crystallization $[46,47]$. The high rate of nucleation in LCB-PP could also be ascribed to gel formation, which arises from the radical-driven synthesis process using peroxides. During these reactions, besides long branches, also chain scission and crosslinking can occur. Even local crosslinking (gel) could lower melt entropy and serve as nuclei during crystallization. On the other hand, branching points, defects in the polymeric chain, decrease the ability to crystallize, and growth rate is slowed, and a formation of $\gamma$-phase is pronounced.

\subsection{The morphology of the blends}

To show and describe the higher structural level of the morphology, namely the detailed lamellar structure and spherulite shape, scanning electron microscopy was employed. The fracture surfaces presented in Figure 6 show a distinct difference between $\alpha-, \beta-$, and $\gamma$-lamellar structure. The smooth crack surface of material containing predominantly $\alpha$-phase reflects fine lamellar structure - sample L-PP (Figure $\left.6 a_{1}\right)$. However, in this micrograph, the $\beta$-phase can also be detected, spatially separated from $\alpha$ phase at the spherulitic level. On the other hand, the distinctly rough surface structure of the L-PP rich in $\beta$-phase is a manifestation of thick lamellae - sample L-PP nucleated (Figure $6 \mathrm{a}_{2}$ ). In the case of LCB-PP and the blends with a higher content of LCB-PP (Figure 6c, 6d), typical spherulites cannot be distinguished. The crystallites of $\alpha$ - and $\gamma$-phases coexist microscopically and cannot be differentiated one from the other in contrast with coexistence $\alpha$ - and $\beta$ phases in L-PP. According to Zeng et al. [36], the LCB-PP can form branched edge-on lamellae during fast cooling and flat-on lamellar structure upon slow crystallization. According to Ni et al. [48], the LCB structure acts as a heterogeneous nucleating agent and influences the growth pattern of the crystal. As a result, the morphology of LCB-PP may have been a mixture that contains rodlike, disklike, and spherulite crystallites.

\section{Conclusions}

The experimental study shows a combined effect of specific nucleation and long-chain branching on resulting polymorphic composition, melting and crystallization behavior, and morphology of polypropylene blends. It is demonstrated that the efficiency of the nucleating agent NU 100 in $\beta$-phase formation decreases sharply with the addition of LCB-PP into blends, the addition of only $5 \mathrm{wt} \%$ of LCB-PP into L-PP leads to a substantial reduction in the trigonal $\beta$-phase content. At the same time, a significant increase in the $\gamma$-phase content can be seen. A positive effect of long-chain branching on $\gamma$-phase formation in prepared blends is observed, independently of presence NU 100. Melting experiments show higher thermodynamic stability of the blends containing a predominant amount of $\alpha$ - and $\gamma$-phases, as compared to the samples rich in $\beta$-phase. Strong nucleation efficiency of LCB-PP is manifested by the shift in the crystallization temperature of the blends. The 


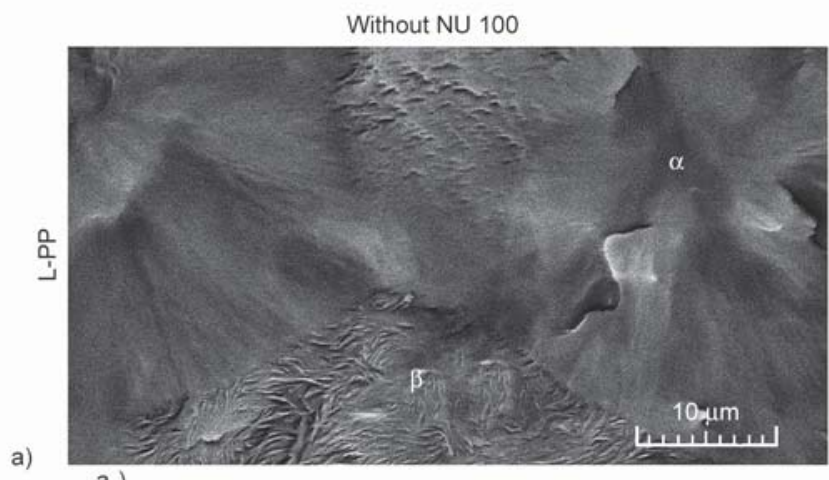

$\left.a_{1}\right)$

b)

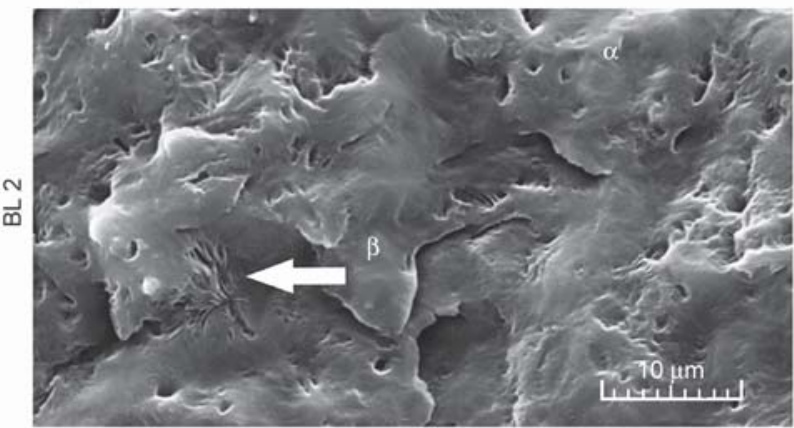

$\left.b_{1}\right)$

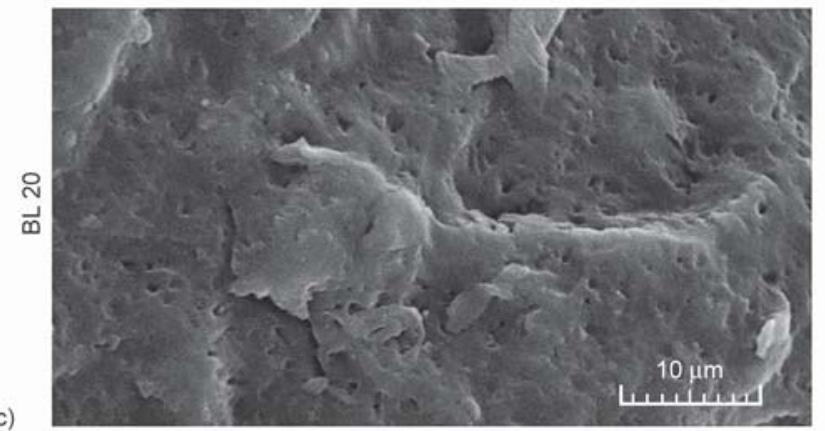

c)

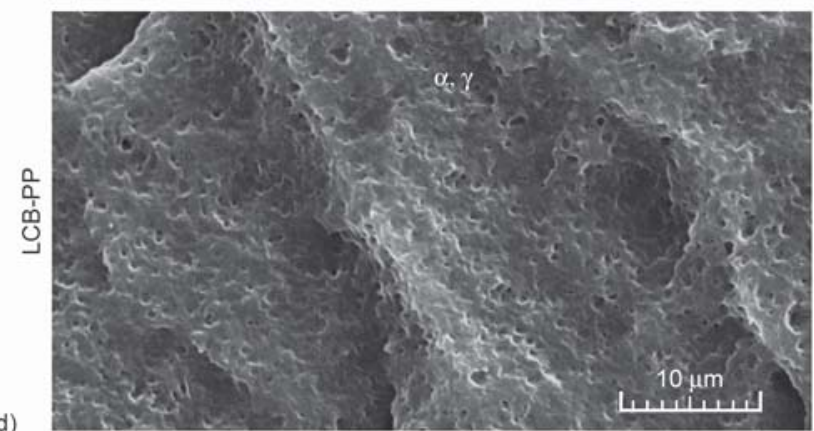

$\left.d_{1}\right)$

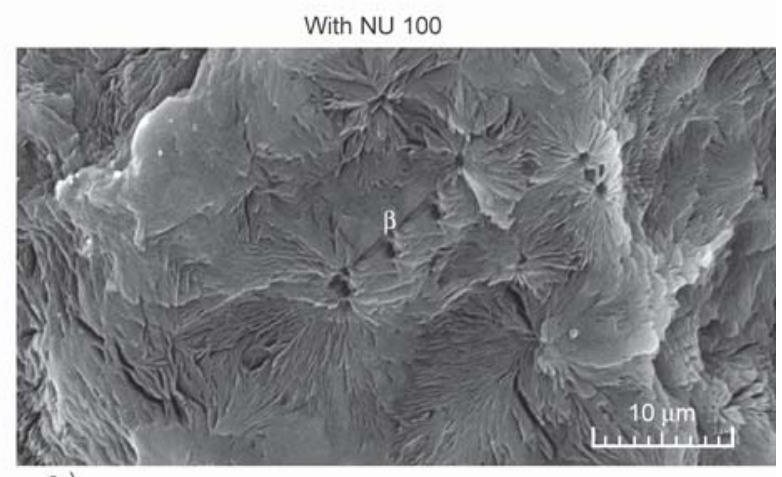

$a_{2}$

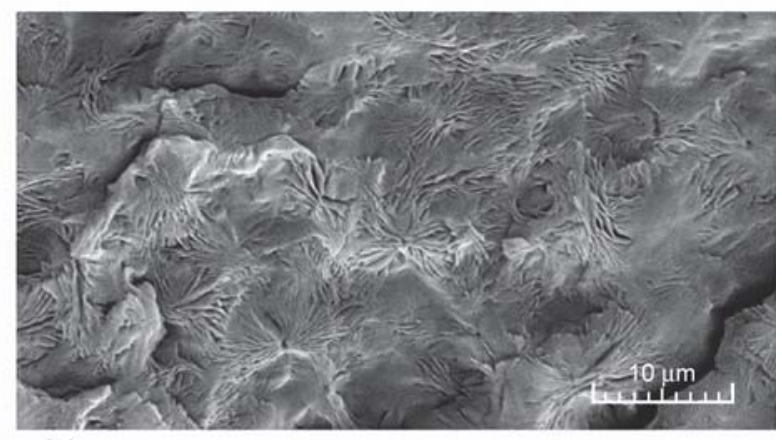

$\mathrm{b}_{2}$ )

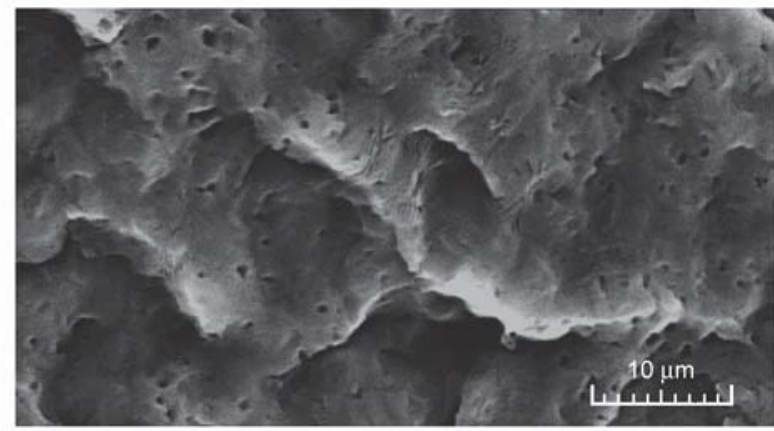

$\mathrm{C}_{2}$ )

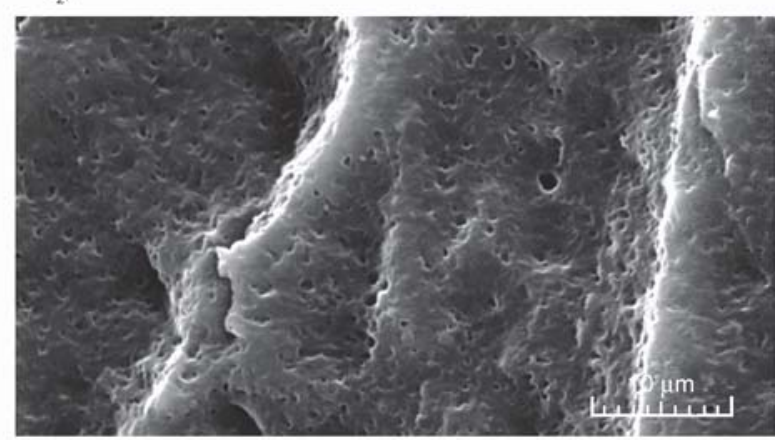

$d_{2}$ )

Figure 6. SEM images of L-PP (a), BL 2 (b), BL 20 (c) and LCB-PP (d) with $\left(a_{2}-d_{2}\right)$ and without $\left(a_{1}-d_{1}\right)$ NU 100.

nucleation efficiency of LCB-PP is ascribed to the self-seeding effect of local crosslinking. On the microscopic level, $\beta$-phase is distinctly separated in spherulites, while $\alpha$ - and $\gamma$-phases coexist on the lamellae level.
The next part of our study will update the knowledge by offering an assessment of the interrelations between the long-chain branching, specific nucleation, and end-use properties of polypropylene blends. 


\section{Acknowledgements}

This article was written with the support of Operational Program for Research, Development, and Education, co-funded by the European Union, within the framework of the project 'International Mobility of Researchers of TBU in Zlín' (Reg. number: CZ.02.2.69/0.0/0.0/16_027/0008464) and by the internal grant agency of the projects IGA/CPS/2018/006 and IGA/CPS/2019/002. The authors kindly acknowledge to Jirina Dohnalova for her help with sample preparation and testing.

\section{References}

[1] Nam G. J., Yoo J. H., Lee J. W.: Effect of long chain branches of polypropylene on rheological properties and foam-extrusion performances. Journal of Applied Polymer Science, 96, 1793-1800 (2005). https://doi.org/10.1002/app.21619

[2] Wang K., Wang S., Wu F., Pang Y., Liu W., Zhai W., Zheng W.: A new strategy for preparation of long-chain branched polypropylene via reactive extrusion with supercritical $\mathrm{CO}_{2}$ designed for an improved foaming approach. Journal of Materials Science, 51, 2705-2715 (2016).

https://doi.org/10.1007/s10853-015-9584-x

[3] Gotsis A. D., Zeevenhoven B. L., Hogt A. H.: The effect of long chain branching on the processability of polypropylene in thermoforming. Polymer Engineering and Science, 44, 973-982 (2004).

https://doi.org/10.1002/pen.20089

[4] McCallum T. J., Kontopoulou M., Park C. B., Muliawan E. B., Hatzikiriakos S. G.: The rheological and physical properties of linear and branched polypropylene blends. Polymer Engineering and Science, 47, 1133-1140 (2007).

https://doi.org/10.1002/pen.20798

[5] Weng W., Hu W., Dekmerzian A. H., Ruff C. J.: Long chain branched isotactic polypropylene. Macromolecules, 35, 3838-3843 (2002).

https://doi.org/10.1021/ma020050j

[6] Langston J. A., Colby R. H., Chung T. C. M., Shimizu F., Suzuki T., Aoki M.: Synthesis and characterization of long chain branched isotactic polypropylene via metallocene catalyst and T-reagent. Macromolecules, 40, 2712-2720 (2007). https://doi.org/10.1021/ma062111+

[7] Krause B., Stephan M., Volkland S., Voigt D., Häußler L., Dorschner H.: Long-chain branching of polypropylene by electron-beam irradiation in the molten state. Journal of Applied Polymer Science, 99, 260-265 (2006). https://doi.org/10.1002/app.22471

[8] Lugăo A. B., Otaguro H., Parra D. F., Yoshiga A., Lima L. F. C. P., Artel B. W. H., Liberman S.: Review on the production process and uses of controlled rheology polypropylene - Gamma radiation versus electron beam processing. Radiation Physics and Chemistry, 76, 16881690 (2007).

https://doi.org/10.1016/j.radphyschem.2007.01.015
[9] Graebling D.: Synthesis of branched polypropylene by a reactive extrusion process. Macromolecules, 35, 46024610 (2002).

https://doi.org/10.1021/ma0109469

[10] Mogilicharla A., Majumdar S., Mitra K.: Multiobjective optimization of long-chain branched propylene polymerization. Polymer Engineering and Science, 55, 10671076 (2015).

https://doi.org/10.1002/pen.23977

[11] Naguib H. E., Park C. B., Panzer U., Reichelt N.: Strategies for achieving ultra low-density polypropylene foams. Polymer Engineering and Science, 42, 14811492 (2002).

https://doi.org/10.1002/pen.11045

[12] Reichelt N., Stadlbauer M., Folland R., Park C. B., Wang J.: PP-blends with tailored foamability and mechanical properties. Cellular Polymers, 22, 315-328 (2003). https://doi.org/10.1177/026248930302200503

[13] Padden F. J., Keith H. D.: Spherulitic crystallization in polypropylene. Journal of Applied Physics, 30, 14791484 (1959). https://doi.org/10.1063/1.1734985

[14] Natta G., Corradini P.: Structure and properties of isotactic polypropylene. Nuovo Cimento, 15, 40-51 (1960). https://doi.org/10.1007/BF02731859

[15] Corradini P., Petraccone V., de Rosa C., Guerra G.: On the structure of the quenched mesomorphic phase of isotactic polypropylene. Macromolecules, 19, 26992703 (1986).

https://doi.org/10.1021/ma00165a006

[16] Gahleitner M., Mileva D., Androsch R., Gloger D., Tranchida D., Sandholzer M., Doshev P.: Crystallinitybased product design: Utilizing the polymorphism of isotactic PP homo- and copolymers. International Polymer Processing, 31, 618-627 (2016).

https://doi.org/10.3139/217.3242

[17] Chvatalová L., Navratilová J., Čermák R., Raab M., Obadal M.: Joint effects of molecular structure and processing history on specific nucleation of isotactic polypropylene. Macromolecules, 42, 7413-7417 (2009). https://doi.org/10.1021/ma9005878

[18] Varga J.: $\beta$-modification of isotactic polypropylene: Preparation, structure, processing, and application. Journal of Macromolecular Science Part B: Physics, 41, 1121-1171 (2002).

https://doi.org/10.1081/MB-120013089

[19] Turner Jones A., Aizlewood J. M., Beckett D. R.: Crystalline forms of isotactic polypropylene. Macromolecular Chemistry and Physics, 75, 134-158 (1964). https://doi.org/10.1002/macp.1964.020750113

[20] Varga J.: Crystallization, melting and supermolecular structure of isotactic polypropylene. in 'Polypropylene structure, blends and composites Vol. 1, Structure and morphology' (ed.: Karger-Kocsis J.) Chapman and Hall, London, 56-115 (1995). 
[21] Varga J.: Supermolecular structure of isotactic polypropylene. Journal of Materials Science, 27, 2557-2579 (1992).

https://doi.org/10.1007/BF00540671

[22] Karger-Kocsis J., Varga J.: Effects of $\beta-\alpha$ transformation on the static and dynamic tensile behavior of isotactic polypropylene. Journal of Applied Polymer Science, 62, 291-300 (1996).

https://doi.org/10.1002/(SICI)10974628(19961010)62:2<291::AID-APP4>3.0.CO;2-S

[23] Raab M., Kotek J., Baldrian J., Grellmann W.: Toughness profile in injection-molded polypropylene: The effect of the $\beta$-modification. Journal of Applied Polymer Science, 69, 2255-2259 (1998).

https://doi.org/10.1002/(SICI)10974628(19980912)69:11<2255::AID-APP18>3.0.CO;2-Y

[24] Obadal M., Cermák R., Stoklasa K., Šimoník J.: Tensile and flexural properties of $\beta$-nucleated polypropylenes. International Polymer Processing, 19, 35-39 (2004). https://doi.org/10.3139/217.1834

[25] Čermák R., Obadal M., Ponížil P., Polášková M., Stoklasa K., Lengálová A.: Injection-moulded $\alpha$ - and $\beta$-polypropylenes: I. Structure vs. processing parameters. European Polymer Journal, 41, 1838-1845 (2005). https://doi.org/10.1016/j.eurpolymj.2005.02.020

[26] Grein C.: Toughness of neat, rubber modified and filled $\beta$-nucleated polypropylene: From fundamentals to applications. in 'Intrinsic molecular mobility and toughness of polymers II. Advances in polymer science' (ed.: Kausch H. H.) Springer, Berlin, 43-104 (2005). https://doi.org/10.1007/b136972

[27] Výchopňová J., Čermák R., Obadal M., Verney V., Commereuc S.: Effect of $\beta$-nucleation on crystallization of photodegraded polypropylene. Journal of Thermal Analysis and Calorimetry, 95, 215-220 (2009). https://doi.org/10.1007/s10973-008-8892-7

[28] Výchopňová J., Čermák R., Obadal M., Raab M., Verney V., Commereuc S.: The role of specific nucleation in polypropylene photodegradation. Polymer Degradation and Stability, 92, 1763-1768 (2007).

https://doi.org/10.1016/j.polymdegradstab.2007.07.010

[29] Obadal M., Čermák R., Raab M., Verney V., Commereuc S., Fraïsse F.: Study on photodegradation of injectionmoulded $\beta$-polypropylenes. Polymer Degradation and Stability, 91, 459-463 (2006).

https://doi.org/10.1016/j.polymdegradstab.2005.01.046

[30] Addink E. J., Beitema J.: Polymorphism of crystalline polypropylene. Polymer, 2, 185-193 (1961).

[31] Krache R., Benavente R., López-Majada J. M., Pereña J. M., Cerrada M. L., Pérez E.: Competition between $\alpha$, $\beta$, and $\gamma$ polymorphs in a $\beta$-nucleated metallocenic isotactic polypropylene. Macromolecules, 40, 6871-6878 (2007).

https://doi.org/10.1021/ma0710636
[32] Pérez E., Zucchi D., Sacchi M. C., Forlini F., Bello A.: Obtaining the $\gamma$ phase in isotactic polypropylene: Effect of catalyst system and crystallization conditions. Polymer, 40, 675-681 (1999).

https://doi.org/10.1016/S0032-3861(98)00291-2

[33] De Rosa C., Aurienma F., Paolillo M., Resconi L., Camurati I.: Crystallization behavior and mechanical properties of regiodefective, highly stereoregular isotactic polypropylene: Effect of regiodefects versus stereodefects and influence of the molecular mass. Macromolecules, 38, 9143-9154 (2005).

https://doi.org/10.1021/ma051004x

[34] Su Z., Wang H., Dong J., Zhang X., Dong X., Zhao Y., Yu J., Han Ch. C., Xu D., Wang D.: Conformation transition and crystalline phase variation of long chain branched isotactic polypropylenes (LCB-iPP). Polymer, 48, 870-876 (2007).

https://doi.org/10.1016/j.polymer.2006.12.013

[35] Agarwal P. K., Somani R. H., Weng W. Q., Mehta A., Yang L., Ran S. F., Liu L. Z., Hsiao B. S.: Shear-induced crystallization in novel long chain branched polypropylenes by in situ rheo-SAXS and -WAXD. Macromolecules, 36, 5226-5235 (2003).

https://doi.org/10.1021/ma0341541

[36] Zeng W., Wang J., Feng Z., Dong J-Y., Yan S.: Morphologies of long chain branched isotactic polypropylene crystallized from melt. Colloid and Polymer Science, 284, 322-326 (2005).

https://doi.org/10.1007/s00396-005-1371-9

[37] Tabatabaei S. H., Carreau P. J., Ajji A.: Rheological and thermal properties of blends of a long-chain branched polypropylene and different linear polypropylenes. Chemical Engineering Science, 64, 4719-4731 (2009). https://doi.org/10.1016/j.ces.2009.04.009

[38] Maroufkhani M., Ebrahim N. G.: Melt rheology of linear and long-chain branched polypropylene blends. Iranian Polymer Journal, 24, 715-724 (2015).

https://doi.org/10.1007/s13726-015-0357-9

[39] Wang X-D., Zhang Y-X., Liu B-G., Du Z-J., Li H-Q.: Crystallization behavior and crystal morphology of linear/long chain branching polypropylene blends. Polymer Journal, 40, 450-454 (2008).

https://doi.org/10.1295/polymj.PJ2007195

[40] Cao J., Zheng Y., Lin T.: Synergistic toughening effect of $\beta$-nucleating agent and long chain branching on polypropylene random copolymer. Polymer Testing, 55, 318327 (2016). https://doi.org/10.1016/j.polymertesting.2016.09.007

[41] Yu K., Jiang H., Zhou H., Mi J., He Y. Wang X.: Evolution of double crystal melting peak in polypropylene foam assisted by $\beta$-nucleating agent and supercritical $\mathrm{CO}_{2}$. Journal of Applied Polymer Science, 135, 46007/146007/10 (2017). https://doi.org/10.1002/app.46007 
[42] Sauer J. A., Pae K. D.: Structure and thermal behavior of pressure-crystallized polypropylene. Journal of Applied Physics, 39, 4959-4968 (1968).

https://doi.org/10.1063/1.1655893

[43] Obadal M., Čermák R., Stoklasa K: Tailoring of threephase crystalline systems in isotactic poly(propylene). Macromolecular Rapid Communications, 26, 1253 1257 (2005).

https://doi.org/10.1002/marc.200500272

[44] Jeon K., Palza H., Quijada R., Alamo R. G.: Effect of comonomer type on the crystallization kinetics and crystalline structure of random isotactic propylene 1-alkene copolymers. Polymer, 50, 832-844 (2009).

https://doi.org/10.1016/j.polymer.2008.10.032

[45] Alamo R. G., Kim M-H., Galante M. J., Isasi J. R., Mandelkern L.: Structural and kinetic factors governing the formation of the $\gamma$ polymorph of isotactic polypropylene. Macromolecules, 32, 4050-4064 (1999).

https://doi.org/10.1021/ma981849r
[46] Auriemma F., De Rosa C., Boscato T., Corradini P.: The oriented $\gamma$ form of isotactic polypropylene. Macromolecules, 34, 4815-4826 (2001).

https://doi.org/10.1021/ma0100504

[47] Auriemma F., Alfonso G. C., de Rosa C.: Polymer crystallization I. From chain microstructure to processing. Advances in Polymer Science, Springer (2017). https://doi.org/10.1007/978-3-319-49203-2

[48] Ni Q-L., Fan J-Q., Dong J-Y.: Crystallization behavior and crystallization kinetic studies of isotactic polypropylene modified by long-chain branching polypropylene. Journal of Applied Polymer Science, 114, 2180-2194 (2009).

https://doi.org/10.1002/app.30363 